\title{
Regorafenib induces extrinsic and intrinsic apoptosis through inhibition of ERK/NF-кB activation in hepatocellular carcinoma cells
}

\author{
JAI-JEN TSAI ${ }^{1-3}$, PO-JUNG PAN ${ }^{3,4}$ and FEI-TING HSU ${ }^{5-7}$ \\ ${ }^{1}$ Division of Gastroenterology, Department of Medicine, National Yang-Ming University Hospital, Yilan 260; \\ ${ }^{2}$ Institute of Traditional Medicine, School of Medicine, National Yang-Ming University, Taipei 112; \\ ${ }^{3}$ Cancer Medical Care Center and ${ }^{4}$ Department of Physical Medicine and Rehabilitation, \\ National Yang-Ming University Hospital, Yilan 260; ${ }^{5}$ Department of Medical Imaging, \\ Taipei Medical University Hospital, Taipei 110; ${ }^{6}$ Research Center of Translational Imaging (TIRC) and \\ ${ }^{7}$ Department of Radiology, College of Medicine, Taipei Medical University, Taipei 110, Taiwan, R.O.C.
}

Received June 24, 2016; Accepted July 20, 2016

DOI: 10.3892/or.2016.5328

\begin{abstract}
The aim of the present study was to investigate the role of NF- $\mathrm{KB}$ inactivation in regorafenib-induced apoptosis in human hepatocellular carcinoma SK-HEP-1 cells. SK-HEP-1 cells were treated with different concentrations of the NF- $\kappa \mathrm{B}$ inhibitor 4-N-[2-(4-phenoxyphenyl)ethyl] quinazoline-4,6-diamine (QNZ) or regorafenib for different periods. The effects of QNZ and regorafenib on cell viability, expression of NF- $\mathrm{kB}$-modulated anti-apoptotic proteins and apoptotic pathways were analyzed by the 3-(4,5-dimethylthiazol-2-yl)-2,5-diphenyltetrazolium bromide (MTT) assay, western blotting, DNA gel electrophoresis, flow cytometry and NF- $\kappa B$ reporter gene assay. Inhibitors of various kinases including AKT, c-Jun N-terminal kinase (JNK), P38 and extracellular signal-regulated kinase (ERK) were used to evaluate the mechanism of regorafenib-induced NF- $\kappa B$ inactivation. The results demonstrated that both QNZ and regorafenib significantly inhibited the expression of antiapoptotic proteins and triggered extrinsic and intrinsic apoptosis. We also demonstrated that regorafenib inhibited NF- $\kappa B$ activation through ERK dephosphorylation. Taken all together, our findings indicate that regorafenib triggers
\end{abstract}

Correspondence to: Dr Fei-Ting Hsu, Department of Medical Imaging, Taipei Medical University Hospital, 252 Wu Hsing Street, Taipei 110, Taiwan, R.O.C.

E-mail: sakiro920@gmail.com

Abbreviations: MMP, mitochondrial membrane potential; C-FLIP, cellular FLICE-like inhibitory protein; XIAP, X-linked inhibitor of apoptosis protein; Mcl-1, myeloid leukemia cell differentiation protein; NF- $\kappa \mathrm{B}$, nuclear factor- $\mathrm{B}$; AKT, protein kinase B; ERK, extracellular signal-regulated kinase; QNZ, NF- $\mathrm{kB}$ inhibitor; JNK, Jun amino-terminal kinases; P38, P38 mitogen-activated protein kinase

Key words: regorafenib, ERK/NF-кB, hepatocellular carcinoma extrinsic and intrinsic apoptosis through suppression of ERK/NF- $\kappa B$ activation in SK-HEP-1 cells.

\section{Introduction}

Apoptosis, or programmed cell death, occurs through both extrinsic and intrinsic pathways, which are modulated by apoptotic proteins including cytochrome $c$, caspase-8 and -3 (1). Morphological and biochemical hallmarks of apoptosis include cell shrinkage, chromatin condensation, DNA fragmentation and formation of apoptotic bodies (2). Anticancer agents and radiation are able to induce apoptotic protein-mediated signal transduction pathways and consequent inhibition of tumor growth $(1,3)$. Anticancer agents and radiation-induced apoptosis can be blocked by overexpression of anti-apoptotic proteins in cancer cells leading to treatment failure (4). Human hepatocellular carcinoma (HCC) is endemic in Asia and among the deadliest types of cancers (5). Overexpression of anti-apoptotic proteins such as cellular FLICE-like inhibitory protein (c-FLIP), myeloid cell leukemia-1 (Mcl-1), and $\mathrm{X}$-linked inhibitor of apoptosis protein (XIAP) has been identified in $\mathrm{HCC}$ and is associated with the poor prognosis of HCC patients (6-8).

Nuclear factor- $\kappa \mathrm{B}(\mathrm{NF}-\kappa \mathrm{B})$ is a transcription factor of a number of oncogenes which modulate tumorigenesis (9). Cancer hallmarks that include self-sufficiency in proliferative growth signals, insensitivity to anti-growth signals, evasion of apoptosis, limitless replicative potential, tissue invasion and metastasis, and sustained angiogenesis have been related to NF- $\mathrm{KB}$-modulated expression of downstream effector proteins (10). Various anticancer agents and radiation not only trigger apoptosis, but also activate expression of NF- $\kappa \mathrm{B}$-induced anti-apoptotic proteins resulting in the reduction of therapeutic efficacy in HCC both in vitro and in vivo $(11,12)$. Constitutive NF- $\mathrm{KB}$ activation is observed in patients with advanced HCC and may be used as a negative prognostic biomarker (13). Therefore, development of NF- $\kappa \mathrm{B}$ signal inhibitors may facilitate the treatment of HCC patients. 
Regorafenib (Stivarga ${ }^{\circledR}$ ) is a multi-kinase inhibitor with a similar chemical structure to sorafenib $\left(\right.$ Nexavar $\left.^{\circledR}\right)$, but has an additional functional group, which produces more potent activity to inhibit oncogenic receptor tyrosine and cytoplasmic signaling kinases (14). Regorafenib has been approved to treat colorectal cancer and gastrointestinal stromal tumors. A recent update of an ongoing phase III clinical trial reported that regorafenib was effective in patients with sorafenibresistant HCC (15). In our previous study, sorafenib, as an inhibitor of $\mathrm{NF}-\kappa \mathrm{B}$ signaling, was found to reduce the expression of NF- $\kappa \mathrm{B}$-modulated anti-apoptotic proteins in $\mathrm{HCC}$ both in vitro and in vivo (12). However, whether regorafenib, an analogue of sorafenib, can induce apoptosis through blockage of NF- $\kappa \mathrm{B}$ activation in HCC cells remains obscure. The aim of the present study was to investigate the role of $\mathrm{NF}-\kappa \mathrm{B}$ inactivation on regorafenib-induced apoptosis in SK-HEP-1 cells using MTT assay, flow cytometry, DNA gel electrophoresis, western blotting and NF- $\kappa \mathrm{B}$ reporter gene assay. ERK, AKT, JNK and P38 inhibitors were used to determine the mechanism of regorafenib-induced $\mathrm{NF}-\kappa \mathrm{B}$ inactivation in $\mathrm{HCC}$.

\section{Materials and methods}

Agents and antibodies. Regorafenib was provided by Bayer Health Care Pharmaceuticals (Whippany, NJ, USA). Dulbecco's modified Eagle's medium (DMEM), fetal bovine serum (FBS), L-glutamine and penicillin-streptomycin (PS) were purchased from Gibco/Life Technologies (Carlsbad, CA, USA). Propidium iodide (PI) and $\mathrm{DiOC}_{6}$ were purchased from BioVision (Mountain View, CA, USA) and Enzo Life Sciences (Farmingdale, NY, USA), respectively. 3-(4,5-Dimethylthiazol-2-yl)-2,5-diphenyltetrazolium bromide (MTT) and RNase were purchased from Sigma-Aldrich (St. Louis, MO, USA) and Fermentas (St. Leon-Rot, Baden-Württemberg, Germany), respectively. Primary antibodies of cleaved-caspase-3, cellular FADD-like IL-1 $\beta$ converting enzyme (FLICE)-inhibitory protein (c-FLIP) and pAKT (Ser473) were purchased from Cell Signaling Technology (Beverly, MA, USA). Primary antibodies of caspase- 8 and X-linked inhibitor of apoptosis protein (XIAP) were obtained from Thermo Fisher Scientific (Fremont, CA, USA). Primary antibodies of ERK, AKT, NF-кB p65, $\beta$-actin and cytochrome $c$ were purchased from Santa Cruz Biotechnology (Santa Cruz, CA, USA). Primary antibodies of MCL-1 and pERK were purchased from BioVision (Milpitas, CA, USA) and Merck Millipore (Billerica, MA, USA), respectively. Secondary antibodies were purchased from Jackson ImmunoResearch (West Grove, PA, USA). Nuclear and Cytoplasmic Extraction and Genomic DNA Miniprep kits were obtained from Chemicon (Temecula, CA, USA) and Axygen Biosciences (Union City, CA, USA), respectively. NF- $\mathrm{B}$ inhibitor 4-N-[2-(4-phenoxyphenyl)ethyl]quinazoline-4,6-diamine (QNZ), AKT inhibitor LY294002, c-Jun N-terminal kinase (JNK) inhibitor SP600125, P38 inhibitor SB203580 and extracellular signal-regulated kinase (ERK) inhibitor PD98059 were purchased from Selleckchem (Houston, TX, USA). NF- $\kappa \mathrm{B}$-luciferrase2 vector $(\mathrm{pNF}-\kappa \mathrm{B} / l u c 2)$ and D-luciferin were obtained from Promega (Madison, WI, USA) and Caliper Life Science (Hopkinton, MA, USA), respectively. Hygromycin B was purchased from Santa Cruz Biotechnology.
Cell culture. SK-HEP-1 cells were gifted by Professor JingGung Chung of the Department of Biological Science and Technology, China Medical University, (Taichung, Taiwan). Cells were cultured in DMEM and supplemented with $10 \%$ FBS, 2 mM L-glutamine and PS (100 U/ml and $100 \mu \mathrm{g} / \mathrm{ml})$ at $37^{\circ} \mathrm{C}$ in an atmosphere of $5 \% \mathrm{CO}_{2}(16)$.

Plasmid transfection and stable clone selection. SK-HEP-1 cells were transfected with $\mathrm{pNF}-\kappa \mathrm{B} / l u c 2$ using JetPEI ${ }^{\mathrm{TM}}$. Cells $\left(1 \times 10^{6}\right)$ were seeded into $10-\mathrm{cm}$ dish and incubated overnight. DNA solution $(10 \mu \mathrm{g} \mathrm{NF- \kappa B} / \mathrm{luc} 2$ plasmid dissolved in $250 \mu \mathrm{l}$ of $150 \mathrm{mM} \mathrm{NaCl}$ ) was mixed with $250 \mu \mathrm{l}$ JetPEI solution (20 $\mu \mathrm{l}$ of JetPEI reagent diluted in $230 \mu \mathrm{l}$ of $150 \mathrm{mM} \mathrm{NaCl}$ ), and then incubated for $30 \mathrm{~min}$ at room temperature to make $500 \mu 1$ DNA/JetPEI mixture. The DNA/JetPEI mixture was added to the SK-HEP-1 cells in a $10-\mathrm{cm}$ diameter dish and incubated for $24 \mathrm{~h}$. After transfection, the cells were cultured in medium containing $200 \mu \mathrm{g} / \mathrm{ml}$ of hygromycin B for two weeks. The surviving clones were subsequently subcultured into 96-well plates. Function of the NF- $\mathrm{NB}$ reporter gene in each clone was assayed using the IVIS 200 Imaging System (Xenogen, Alameda, CA, USA). Cells with functional NF- $\kappa \mathrm{B}$ reporter gene product were renamed as SK-HEP-1/NF- $\kappa \mathrm{B}-l u c 2$ cells (12).

MTT assay. SK-HEP-1 cells were seeded into 96-well plates at a density of $3 \times 10^{4}$ cells/well and incubated overnight. Cells were treated with different concentrations of QNZ (0-0.4 $\mu \mathrm{M}$ in $0.1 \%$ DMSO) or regorafenib (0-50 $\mu \mathrm{M}$ in $0.1 \%$ DMSO) for different periods, and then the change in cell viability was determined with the MTT assay as previously described (17).

Detection of mitochondrial membrane potential (MMP). SK-HEP-1 cells were seeded into 12 -well plates at a density of $2 \times 10^{5}$ cells/well and incubated overnight. Cells were treated with $0.4 \mu \mathrm{M}$ QNZ or $20 \mu \mathrm{M}$ regorafenib for different periods. Cells were harvested by centrifugation and washed twice with phosphate-buffered saline (PBS), and then stained with DiOC $_{6}$ solution $(4 \mu \mathrm{M} \mathrm{DiOC}$ in $500 \mu \mathrm{l} \mathrm{PBS})$ for $30 \mathrm{~min}$ at $37^{\circ} \mathrm{C}$. Detection of MMP was performed using flow cytometry (FACS101; FACScan; Becton-Dickinson, Franklin Lakes, NJ, USA) as described by Wang et al (18).

Analysis of the sub-G $G_{1}$ population. SK-HEP-1 cells were seeded into 12 -well plates at a density of $2 \times 10^{5}$ cells/well and incubated overnight. Cells were treated with $0.4 \mu \mathrm{M}$ QNZ or $20 \mu \mathrm{M}$ regorafenib for different periods. The cells were harvested by centrifugation and fixed with $70 \%$ ethanol and incubated overnight at $-20^{\circ} \mathrm{C}$. Cells were washed twice with PBS and then stained with $500 \mu \mathrm{l}$ of PI buffer $(40 \mu \mathrm{g} / \mathrm{ml} \mathrm{PI}$, $100 \mu \mathrm{g} / \mathrm{ml}$ RNase and $1 \%$ Triton X-100 in PBS) for $1 \mathrm{~h}$ in darkness at room temperature. Detection of the sub- $\mathrm{G}_{1}$ cell population was performed using flow cytometry (FACS101; FACScan) as described by Huang et al (19).

Western blot assay. SK-HEP-1 cells $\left(3 \times 10^{6}\right)$ were seeded into $10-\mathrm{cm}$ diameter dishes and incubated overnight. Then, the cells were treated with $0.4 \mu \mathrm{M}$ QNZ or $20 \mu \mathrm{M}$ regorafenib for different periods. Lysis buffer $(50 \mathrm{mM}$ Tris- $\mathrm{HCl} \mathrm{pH} 8.0$, $120 \mathrm{mM} \mathrm{NaCl}, 0.5 \% \mathrm{NP}-40$ and $1 \mathrm{mM}$ phenylmethanesulfonyl 

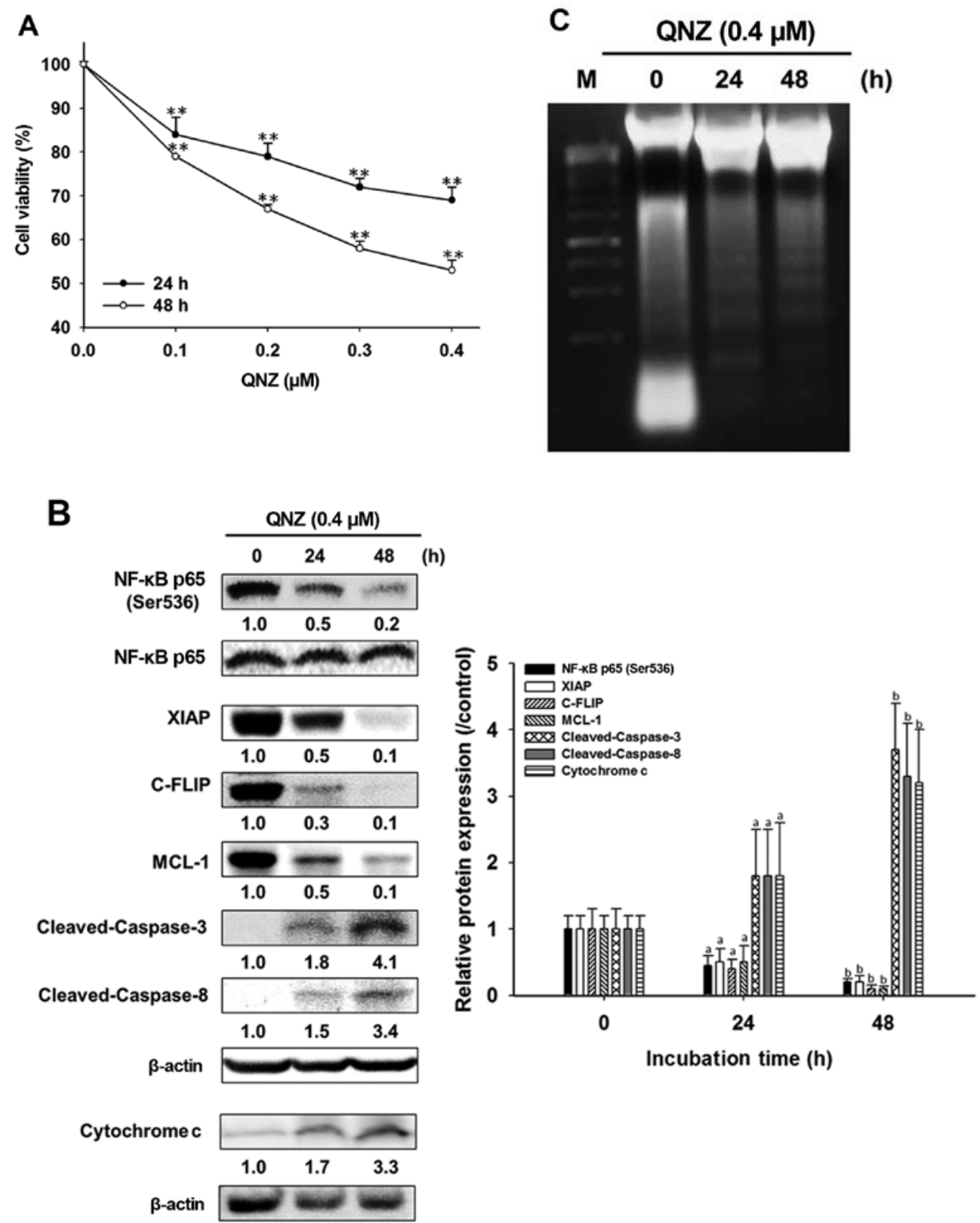

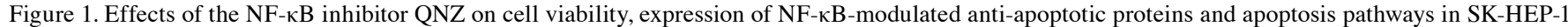
cells. SK-HEP-1 cells were treated with different concentrations ( $0,0.1,0.2,0.3$ and $0.4 \mu \mathrm{M}$ in $0.1 \%$ DMSO) of QNZ for 24 and 48 h. (A) Change in cell viability was determined with the MTT assay. " "p $<0.01$. (B) Protein levels of NF-kB p65 (Ser536), XIAP, c-FLIP, MCL-1, cleaved-caspase-3 and -8 , and cytochrome $c$ were evaluated using western blot assay. ${ }^{\mathrm{a}} \mathrm{p}<0.05$ and ${ }^{\mathrm{b}} \mathrm{p}<0.01$ as compared with the control. (C) Detection of DNA fragmentation was performed using gel electrophoresis.

fluoride) was used for total protein extraction from the cells in the different treatment groups. Cytosolic proteins from cells in each group were extracted using a cytosol extraction kit following the instructions provided by the manufacturer.

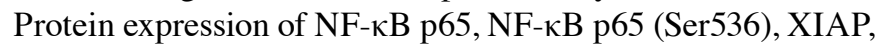
Mcl-1, c-FLIP, cleaved-caspase-3, caspase-8, cytochorme $c$, ERK, pERK, AKT and pAKT were evaluated with western blot assay as described by Ting et al (20). Quantification of protein bands was performed using ImageJ software (National Institutes of Health, Bethesda, MD, USA).

Detection of DNA fragmentation. SK-HEP-1 cells were seeded into 6-well plates at a density of $1 \times 10^{6}$ cells/well and incubated overnight, and then treated with $0.4 \mu \mathrm{M}$ QNZ or $20 \mu \mathrm{M}$ regorafenib for different periods. Genomic DNA from the cells was purified using the GenElute ${ }^{\mathrm{TM}}$ Mammalian Genomic DNA Miniprep kit (Sigma-Aldrich) following the instructions provided by the manufacturer. Analysis of DNA fragmentation was performed using 1.5\% agarose gel electrophoresis (12).

$N F-\kappa B$ reporter gene assay. SK-HEP-1 cells were seeded into 96-well plates at a density of $3 \times 10^{4}$ cells/well and incubated overnight. The detailed conditions for the different treatment groups are provided in detail in the figure legends. D-luciferin solution (500 $\mu \mathrm{M}$ D-luciferin in $100 \mu \mathrm{l} \mathrm{PBS}$ ) was added to each well, and photon signal was acquired for 1 min using the IVIS 
D

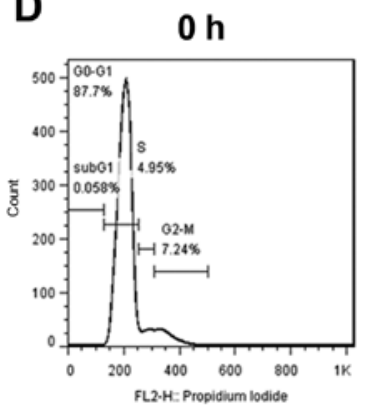

$24 \mathrm{~h}$

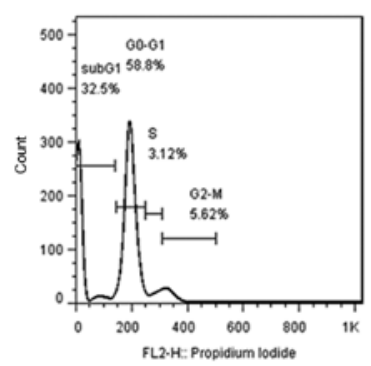

$48 \mathrm{~h}$

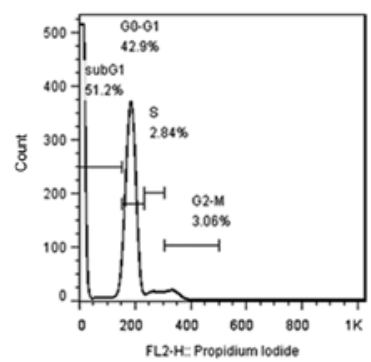

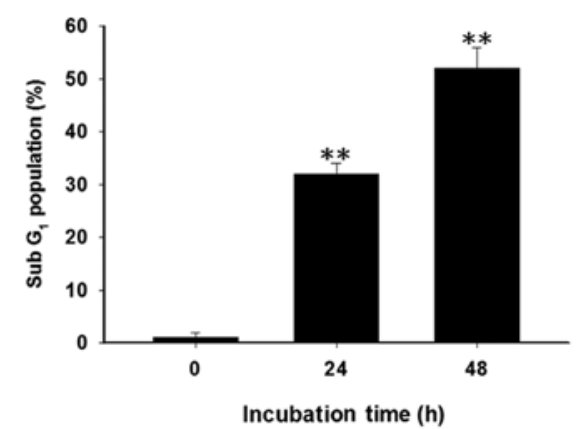

E

$\mathbf{O h}$

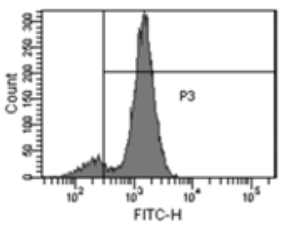

$24 \mathrm{~h}$

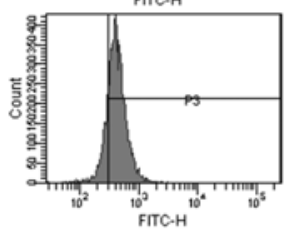

$48 \mathrm{~h}$
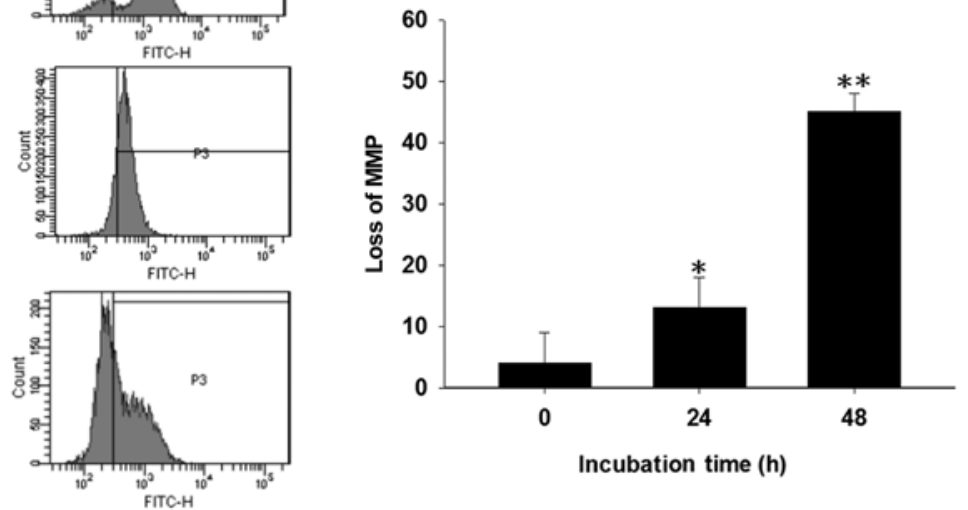

Figure 1. Continued. (D) Determination of the sub- $\mathrm{G}_{1}$ cell population was carried out using flow cytometry. ${ }^{* *} \mathrm{p}<0.01$ as compared with the control. (E) The change in MMP was investigated using flow cytometry. ${ }^{*} \mathrm{p}<0.05$ and ${ }^{* *} \mathrm{p}<0.01$ as compared with the control.

200 Imaging System. Relative NF- $\kappa$ B activity was corrected by cell viability which was evaluated by the MTT assay as previously described (17).

Statistical analysis. Results are all representative of at least three independent experiments. Statistical significance was determined using the Student's t-test. p-values of $<0.05$ were considered statistically significant.

\section{Results}

$N F-\kappa B$ inhibitor diminishes the expression of anti-apoptotic proteins and induces both extrinsic and intrinsic apoptosis in the SK-HEP-1 cells. In order to verify the effects of NF- $\mathrm{BB}$ inactivation on pro-apoptotic and anti-apoptotic signal transduction, SK-HEP-1 cells were initially treated with different concentrations of QNZ for different periods. Subsequently, cell viability, expression of NF- $\kappa \mathrm{B}$ p65 (Ser536), anti-apoptotic and pro-apoptotic proteins, and the effects of apoptosis were evaluated with MTT assay, western blotting, DNA gel electrophoresis and flow cytometry. Fig. 1A indicates that QNZ significantly reduced cell viability in a dose- and timedependent manner as compared to that noted in the control cells (vehicle treatment with $0.1 \%$ DMSO). Fig. 1B shows that QNZ not only inhibited expression of NF-кB p65 (Ser536) and anti-apoptotic proteins (XIAP, MCL-1 and c-FLIP), but also increased levels of pro-apoptotic proteins (cleavedcaspase-3 and -8 , and cytochrome $c$ ). DNA fragmentation 

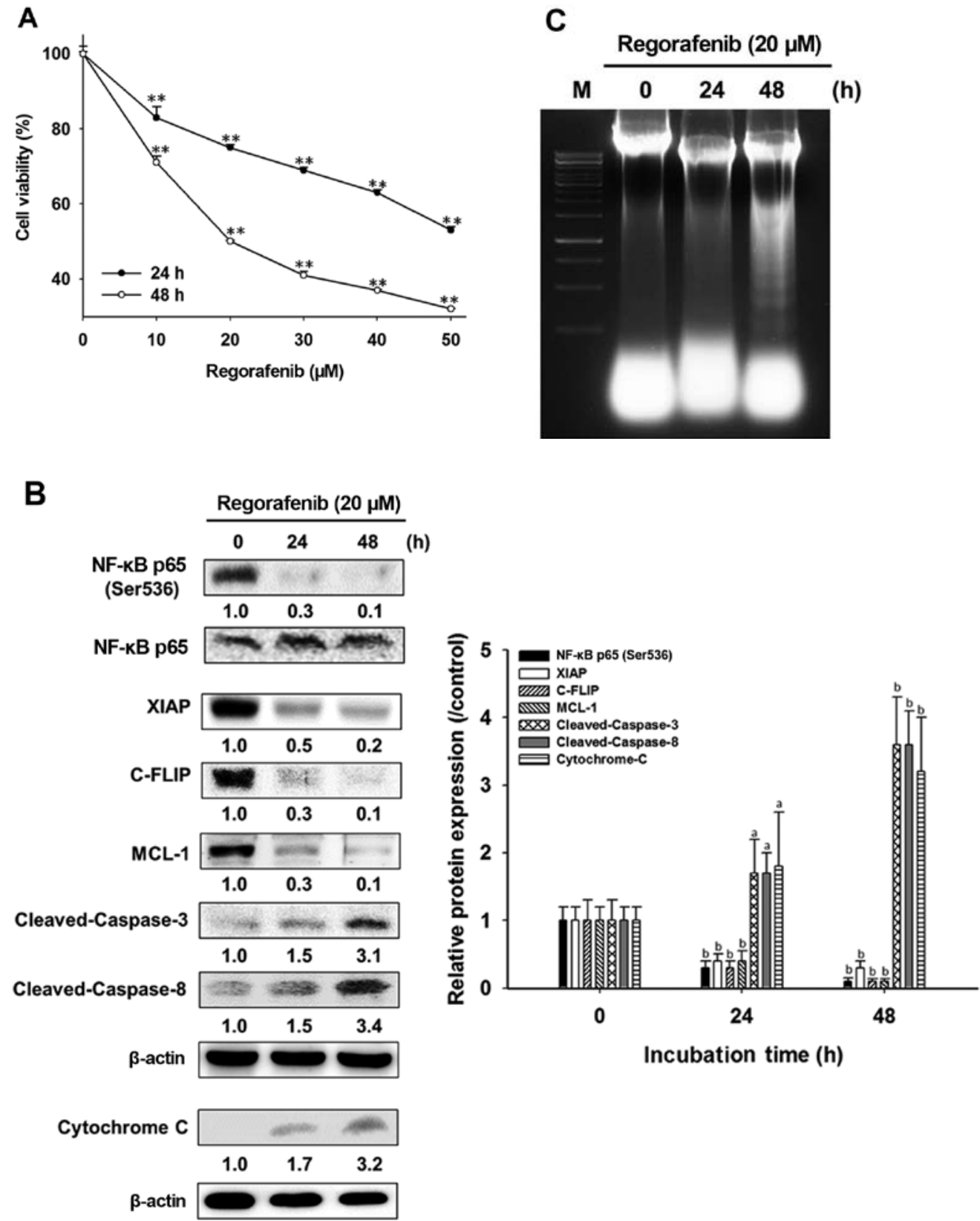

Figure 2. Effects of regorafenib on cell viability, expression of NF-кB-modulated anti-apoptotic proteins and apoptosis pathways in SK-Hep1 cells. Cells were treated with different concentration (0,10,20,30,40 and $50 \mu \mathrm{M}$ in $0.1 \%$ DMSO) of regorafenib for 24 and $48 \mathrm{~h}$. (A) Change in cell viability was determined with MTT assay. ${ }^{* *}$ p $<0.01$. (B) Protein levels of NF- $\mathrm{kB}$ p65 (Ser536), XIAP, c-FLIP, MCL-1, cleaved-caspase-3 and -8 , and cytochrome $c$ were evaluated by western blot assay. ${ }^{\mathrm{a}} \mathrm{p}<0.05$ and ${ }^{\mathrm{b}} \mathrm{p}<0.01$ as compared with the control. (C) Detection of DNA fragmentation was performed using gel electrophoresis.

is one of the apoptotic hallmarks and QNZ-induced DNA fragmentation is demonstrated in Fig. 1C. Apoptosis also can be measured by flow cytometry to detect the sub- $\mathrm{G}_{1}$ cell population and MMP. The sub- $\mathrm{G}_{1}$ cell population and loss of MMP were significantly enhanced by regorafenib treatment in a time-dependent manner as compared to the control (Fig. 1D and E).

Regorafenib inhibits expression of $N F-\kappa B$-modulated anti-apoptotic proteins and induces both extrinsic and intrinsic apoptosis in the SK-HEP-1 cells. The SK-HEP-1 cells were treated with different concentrations of regorafenib for different periods. Cell viability, expression of NF- $\mathrm{KB}$ p65 (Ser536), expression of anti-apoptotic and pro-apoptotic proteins, and regorafenib effects on apoptosis were evaluated with MTT assay, western blotting, DNA gel electrophoresis, and flow cytometry. Regorafenib significantly decreased cell viability in a dose- and time-dependent manner as compared to that noted in the control cells (Fig. 2A). Regorafenib also significantly inhibited expression of NF- $\mathrm{KB}$ p65 (Ser536) and anti-apoptotic proteins (XIAP, MCL-1 and c-FLIP) while increased the levels of pro-apoptotic proteins (cleaved-caspase-3 and -8, and cytochrome $c$ ) in a timedependent manner as compared to the control group (Fig. 2B). Fig. $2 \mathrm{C}$ shows that regorafenib induced DNA fragmentation and significantly induced the sub- $\mathrm{G}_{1}$ cell population and loss of MMP in a time-dependent manner as compared to the control (Fig. 2D and E). 
D

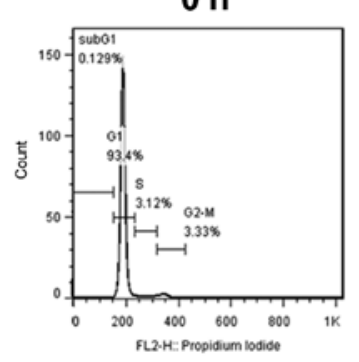

$24 \mathrm{~h}$

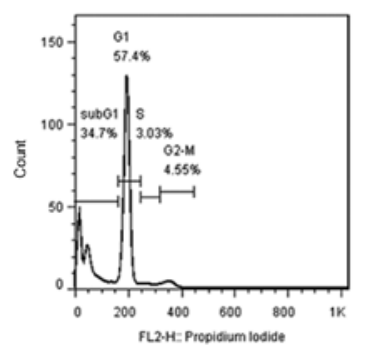

$48 \mathrm{~h}$

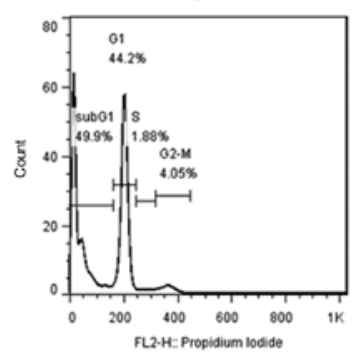

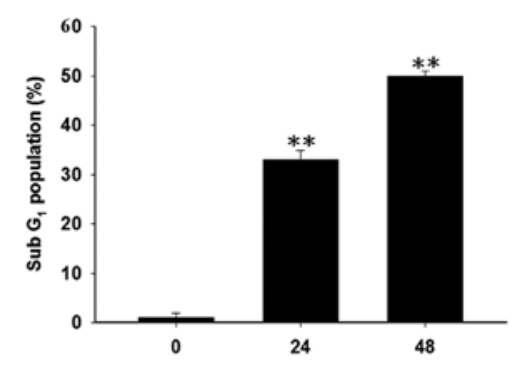

Incubation time (h)

\section{E}
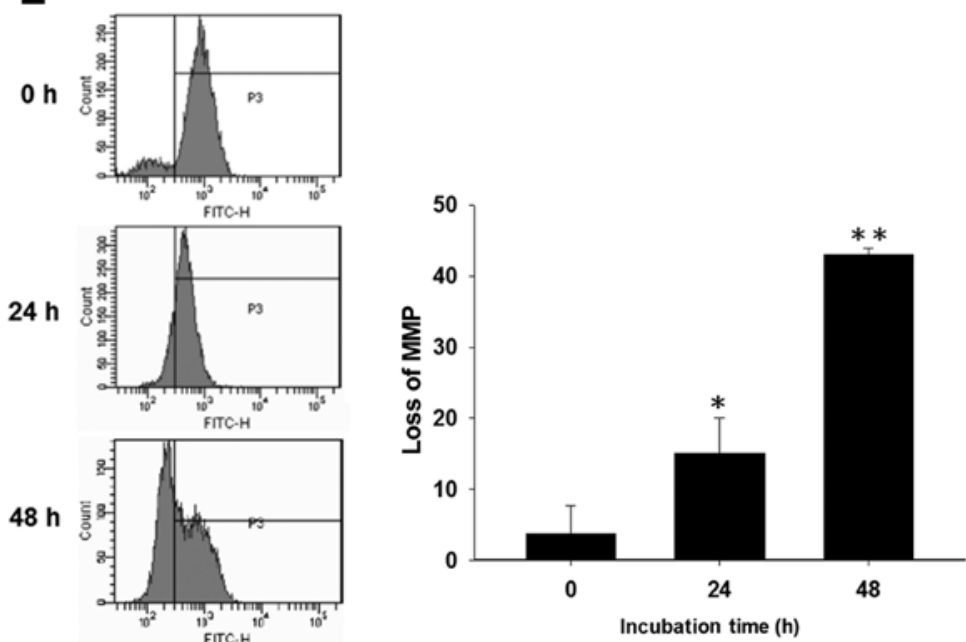

Figure 2. Continued. (D) Determination of Sub $\mathrm{G}_{1}$ population was performed using flow cytometry. ${ }^{* *} \mathrm{p}<0.01$ as compared with the control. (E) Change of MMP was investigated using flow cytometry. " $\mathrm{p}<0.05$ and ${ }^{* *} \mathrm{p}<0.01$ as compared with the control.

Regorafenib inhibits $N F-\kappa B$ activation through ERK dephosphorylation in the SK-HEP-1 cells. We found that regorafenib reduced NF- $\mathrm{KB}$ activation and this turns regorafenib into an inhibitor of NF- $\mathrm{KB}$ signaling. In the next step, we used different kinase (AKT, JNK, P38 and ERK) inhibitors to investigate the mechanism of regorafenib-induced NF- $\mathrm{KB}$ inactivation in the SK-HEP-1 cells. Fig. 3A and B shows that regorafenib, QNZ (NF- $\mathrm{KB}$ inhibitor) and the ERK inhibitor (PD98059) significantly reduced NF- $\mathrm{\kappa B}$ activation. Fig. $3 \mathrm{C}$ indicates that regorafenib also inhibited ERK and AKT phosphorylation in a time-dependent manner in the SK-HEP-1 cells.

\section{Discussion}

Regorafenib, a sorafenib analogue, has been approved for the treatment of metastatic colorectal cancer and advanced gastrointestinal stromal tumors (15). Sorafenib, as an inhibitor of NF- $\mathrm{KB}$ signaling, was indicated in our previous study to reduce the expression of NF- $\mathrm{KB}$-modulated anti-apoptotic proteins and trigger the apoptotic pathway in HCC both in vitro and in vivo (12). However, whether regorafenib induces apoptosis through inhibition of NF- $\mathrm{KB}$ activation in $\mathrm{HCC}$ cells requires elucidation. Therefore, we evaluated the effects of regorafenib on NF- $\mathrm{KB}$ inhibition-related apoptosis and the mechanism in HCC SK-HEP-1 cells in vitro. First, we found that the NF- $\kappa B$ inhibitor QNZ reduced NF- $\kappa B$ activation and anti-apoptotic protein levels (XIAP, c-FLIP and MCL-1) while triggered extrinsic and intrinsic apoptotic pathways (Fig. 1A-E). Secondly, regorafenib as inhibitor of NF- $\mathrm{kB}$ signaling also suppressed NF- $\mathrm{KB}$ activation and anti-apoptotic protein levels, while induced extrinsic and intrinsic apoptotic pathways (Fig. 2A-E). Finally, we found that the ERK inhibitor 
A
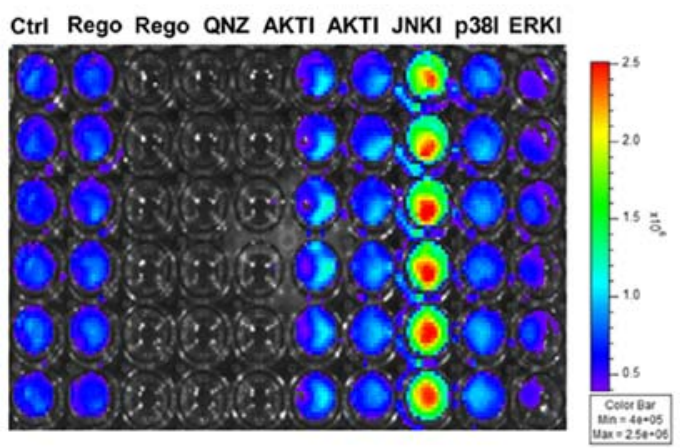

B
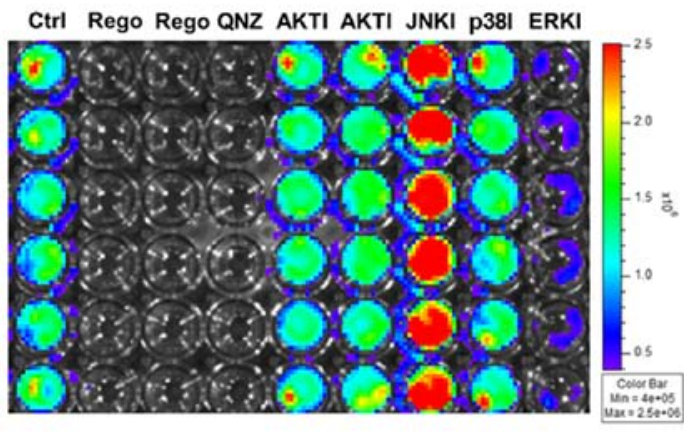

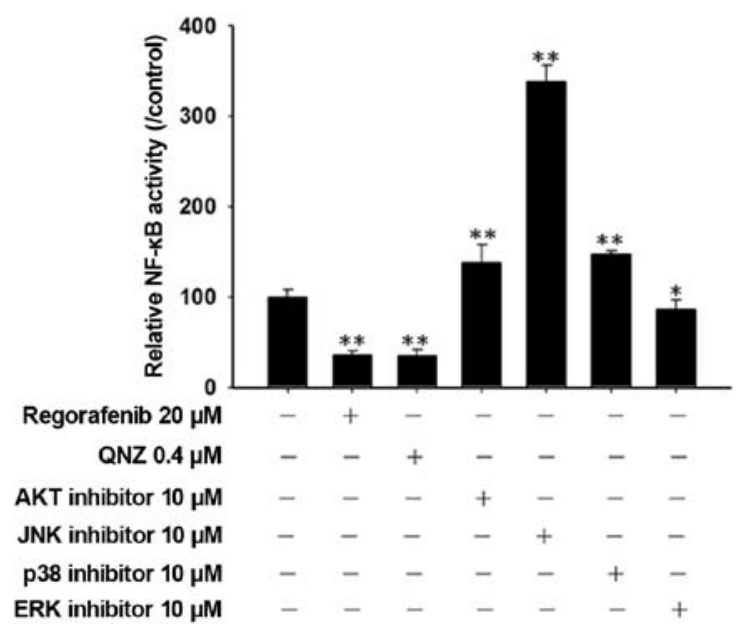

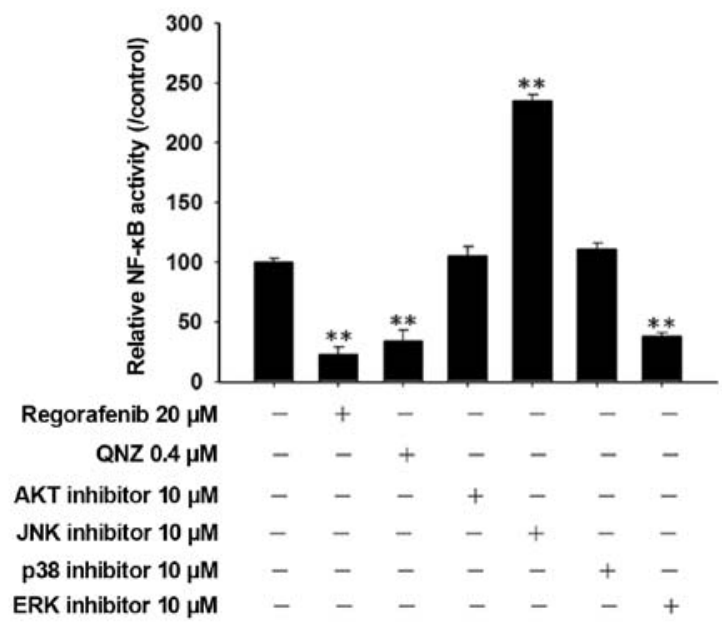
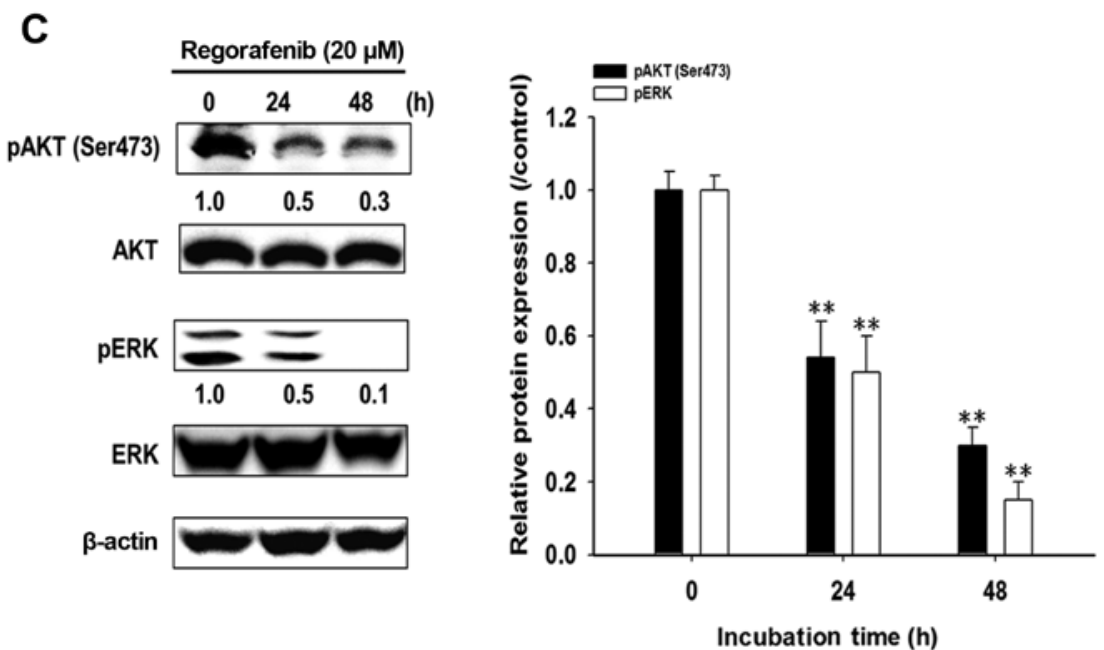

Figure 3. Effects of different kinase inhibitors on NF- $\mathrm{B}$ activation and the effects of regorafenib on ERK and AKT phosphorylation in SK-Hep1 cells. SK-Hep1 cells were treated with $20 \mu \mathrm{M}$ regorafenib, $0.4 \mu \mathrm{M}$ QNZ and $10 \mu \mathrm{M}$ various kinase (AKT, JNK, P38 and ERK) inhibitors for 24 and 48 h. (A) NF- $\kappa B$ activation was evaluated with NF- $\kappa$ B reporter gene assay after treatment for $24 \mathrm{~h}$. Images were acquired by IVIS 200. (B) NF- $\mathrm{B}$ activation was evaluated with NF- $\mathrm{kB}$ reporter gene assay after treatments for $48 \mathrm{~h}$. Images were acquired by IVIS 200. (C) Protein expression of phosphorylated ERK and AKT (Ser473) was determined with western blot assay. ${ }^{*} \mathrm{p}<0.05$ and $^{* *} \mathrm{p}<0.01$ as compared with the control.

reduced NF- $\mathrm{B}$ activation and regorafenib diminished ERK phosphorylation (Fig. 3A and B).

Expression of anti-apoptotic proteins such as XIAP, c-FLIP and MCL-1 is linked to constitutive NF- $\mathrm{KB}$ activation in cancer cells $(12,21)$. XIAP can interact with the active site of caspase- 3 resulting in inhibition of caspase3-mediated apoptosis (22). c-FLIP, a caspase-8 inhibitor, disrupts caspase- 8 and prevents initiation of the extrinsic 
apoptotic pathway (23). MCL-1 suppresses loss of MMP and cytochrome $c$ release from mitochondria that subsequently leads to inhibition of the intrinsic apoptotic pathway $(24,25)$. The present study results demonstrated that both the NF- $\mathrm{B}$ inhibitor and regorafenib inhibited $N F-\kappa B$ activation, reduced anti-apoptotic protein (XIAP, c-FLIP and MCL-1) expression, and activated extrinsic and intrinsic apoptotic pathways. Chen et al suggested that regorafenib activates NF- $\kappa$ B-regulated expression of p53-upregulated modulator of apoptosis (PUMA) and inhibits colorectal tumor growth (26). $\mathrm{RAF} / \mathrm{mitogen}$-activated protein kinase kinase (MEK)/ ERK and phosphoinositide 3-kinase (PI3K)/AKT signaling transduction are the most critical pathways in the development and progression of HCC. Activation of ERK and AKT can be used as biomarkers to predict poor prognosis in HCC (27). Sorafenib induces apoptosis and inhibits angiogenesis in $\mathrm{HCC}$ via blockage of the RAF/MEK/ERK pathway. However, AKT activation is not inhibited by sorafenib (28). Fig. 3C shows that regorafenib significantly reduced both ERK and AKT phosphorylation. NF- $\kappa \mathrm{B}$ can be activated through different kinases, such as AKT, JNK, P38 or ERK in different types of cancer cells (12,29-30). We used inhibitors of AKT, JNK, P38 and ERK to verify the mechanism of regorafenib-induced NF- $\kappa \mathrm{B}$ inactivation in the SK-HEP-1 cells. We found that the ERK inhibitor revealed similar effects in the inhibition of NF- $\kappa \mathrm{B}$ activation as regorafenib or QNZ (Fig. 3A and B). Therefore, we suggest that regorafenib inhibits $N F-\kappa B$ activation via dephosphorylation of ERK. In previous studies, we also found that sorafenib inhibited NF- $\mathrm{NB}$-modulated tumor progression through suppression of ERK activation in HCC Huh7 cells $(12,17)$.

In conclusion, the present study demonstrated that regorafenib triggered extrinsic and intrinsic apoptotic pathways through blockage of ERK/NF- $\kappa \mathrm{B}$ activation in SK-HEP-1 cells in vitro. We propose that regorafenib may be a potential anticancer agent for the treatment of advanced HCC.

\section{Acknowledgements}

The present study was supported by a grant to J.-J.T. (RD2016-020) from the National Yang-Ming University Hospital (Yilan, Taiwan). We acknowledge the technical services provided by the Clinical Medicine Research Laboratory of National Yang-Ming University Hospital.

\section{References}

1. Hassan M, Watari H, AbuAlmaaty A, Ohba Y and Sakuragi N: Apoptosis and molecular targeting therapy in cancer. Biomed Res Int 2014: 150845, 2014.

2. Fulda S and Debatin KM: Apoptosis signaling in tumor therapy. Ann NY Acad Sci 1028: 150-156, 2004.

3. Verheij M and Bartelink H: Radiation-induced apoptosis. Cell Tissue Res 301: 133-142, 2000.

4. Pommier Y, Sordet O, Antony S, Hayward RL and Kohn KW: Apoptosis defects and chemotherapy resistance: Molecular interaction maps and networks. Oncogene 23: 2934-2949, 2004.

5. Cheng AL, Kang YK, Chen Z, Tsao CJ, Qin S, Kim JS, Luo R, Feng J, Ye S, Yang TS, et al: Efficacy and safety of sorafenib in patients in the Asia-Pacific region with advanced hepatocellular carcinoma: A phase III randomised, double-blind, placebo-controlled trial. Lancet Oncol 10: 25-34, 2009.

6. Du X, Bao G, He X, Zhao H, Yu F, Qiao Q, Lu J and Ma Q: Expression and biological significance of c-FLIP in human hepatocellular carcinomas. J Exp Clin Cancer Res 28: 24-31, 2009.
7. Fleischer B, Schulze-Bergkamen H, Schuchmann M, Weber A, Biesterfeld S, Müller M, Krammer PH and Galle PR: Mcl-1 is an anti-apoptotic factor for human hepatocellular carcinoma. Int J Oncol 28: 25-32, 2006.

8. Augello C, Caruso L, Maggioni M, Donadon M, Montorsi M, Santambrogio R, Torzilli G, Vaira V, Pellegrini C, Roncalli M, et al: Inhibitors of apoptosis proteins (IAPs) expression and their prognostic significance in hepatocellular carcinoma. BMC Cancer 9: 125-134, 2009.

9. Chen JH, Chen WL and Liu YC: Amentoflavone induces antiangiogenic and anti-metastatic effects through suppression of NF- $\mathrm{B} \mathrm{activation} \mathrm{in} \mathrm{MCF-7} \mathrm{cells.} \mathrm{Anticancer} \mathrm{Res} \mathrm{35:} \mathrm{6685-6693,}$ 2015.

10. Baud V and Karin M: Is NF-kappaB a good target for cancer therapy? Hopes and pitfalls. Nat Rev Drug Discov 8: 33-40, 2009.

11. Hsu FT, Liu YC, Chiang IT, Liu RS, Wang HE, Lin WJ and Hwang JJ: Sorafenib increases efficacy of vorinostat against human hepatocellular carcinoma through transduction inhibition of vorinostat-induced ERK/NF- $\mathrm{BB}$ signaling. Int J Oncol 45: 177-188, 2014.

12. Hsu FT, Liu YC, Liu TT and Hwang JJ: Curcumin sensitizes hepatocellular carcinoma cells to radiation via suppression of radiation-induced NF- $\kappa \mathrm{B}$ activity. Biomed Res Int 2015: 363671,2015

13. Jin Y, Chen J, Feng Z, Fan W, Wang Y, Li J and Tong D: The expression of Survivin and NF- $\kappa$ B associated with prognostically worse clinicopathologic variables in hepatocellular carcinoma. Tumour Biol 35: 9905-9910, 2014.

14. Ravi S and Singal AK: Regorafenib: An evidence-based review of its potential in patients with advanced liver cancer. Core Evid 9: 81-87, 2014.

15. Tai WT, Chu PY, Shiau CW, Chen YL, Li YS, Hung MH, Chen LJ, Chen PL, Su JC, Lin PY, et al: STAT3 mediates regorafenib-induced apoptosis in hepatocellular carcinoma. Clin Cancer Res 20: 5768-5776, 2014.

16. Ma CY,Ji WT, Chueh FS, Yang JS, Chen PY, Yu CC and Chung JG: Butein inhibits the migration and invasion of SK-HEP-1 human hepatocarcinoma cells through suppressing the ERK, JNK, p38, and uPA signaling multiple pathways. J Agric Food Chem 59: 9032-9038, 2011.

17. Chiang IT, Liu YC, Wang WH, Hsu FT, Chen HW, Lin WJ, Chang WY and Hwang JJ: Sorafenib inhibits TPA-induced MMP-9 and VEGF expression via suppression of ERK/NF- $\kappa B$ pathway in hepatocellular carcinoma cells. In Vivo 26: 671-681, 2012.

18. Wang WH, Chiang IT, Ding K, Chung JG, Lin WJ, Lin SS and Hwang JJ: Curcumin-induced apoptosis in human hepatocellular carcinoma j5 cells: Critical role of $\mathrm{Ca}^{+2}$-dependent pathway. Evid Based Complement Alternat Med 2012: 512907, 2012.

19. Huang SH, Wu LW, Huang AC, Yu CC, Lien JC, Huang YP, Yang JS, Yang JH, Hsiao YP, Wood WG, et al: Benzyl isothiocyanate (BITC) induces $\mathrm{G}_{2} / \mathrm{M}$ phase arrest and apoptosis in human melanoma A375.S2 cells through reactive oxygen species (ROS) and both mitochondria-dependent and death receptor-mediated multiple signaling pathways. J Agric Food Chem 60: 665-675, 2012.

20. Ting CY, Wang HE, Yu CC, Liu HC, Liu YC and Chiang IT: Curcumin triggers DNA damage and inhibits expression of DNA repair proteins in human lung cancer cells. Anticancer Res 35: 3867-3873, 2015.

21. Liu H, Yang J, Yuan Y, Xia Z, Chen M, Xie L, Ma X, Wang J, Ouyang $\mathrm{S}, \mathrm{Wu} \mathrm{Q}$, et al: Regulation of Mcl-1 by constitutive activation of NF- $\mathrm{KB}$ contributes to cell viability in human esophageal squamous cell carcinoma cells. BMC Cancer 14: 98-110, 2014

22. Scott FL, Denault JB, Riedl SJ, Shin H, Renatus M and Salvesen GS: XIAP inhibits caspase-3 and -7 using two binding sites: Evolutionarily conserved mechanism of IAPs. EMBO J 24: 645-655, 2005.

23. Elmore S: Apoptosis: A review of programmed cell death. Toxicol Pathol 35: 495-516, 2007.

24. Perciavalle RM and Opferman JT: Delving deeper: MCL-1's contributions to normal and cancer biology. Trends Cell Biol 23: 22-29, 2013

25. Morciano G, Giorgi C, Balestra D, Marchi S, Perrone D, Pinotti M and Pinton P: Mcl-1 involvement in mitochondrial dynamics is associated with apoptotic cell death. Mol Biol Cell 27: 20-34, 2016. 
26. Chen D, Wei L, Yu J and Zhang L: Regorafenib inhibits colorectal tumor growth through PUMA-mediated apoptosis. Clin Cancer Res 20: 3472-3484, 2014

27. Schmitz KJ, Wohlschlaeger J, Lang H, Sotiropoulos GC, Malago M, Steveling K, Reis H, Cicinnati VR, Schmid KW and Baba HA: Activation of the ERK and AKT signalling pathway predicts poor prognosis in hepatocellular carcinoma and ERK activation in cancer tissue is associated with hepatitis $\mathrm{C}$ virus infection. J Hepatol 48: 83-90, 2008.

28. Liu L, Cao Y, Chen C, Zhang X, McNabola A, Wilkie D, Wilhelm S, Lynch $M$ and Carter C: Sorafenib blocks the RAF/MEK/ERK pathway, inhibits tumor angiogenesis, and induces tumor cell apoptosis in hepatocellular carcinoma model PLC/PRF/5. Cancer Res 66: 11851-11858, 2006.
29. Cheng JC, Chou CH, Kuo ML and Hsieh CY: Radiation-enhanced hepatocellular carcinoma cell invasion with MMP-9 expression through PI3K/Akt/NF-kappaB signal transduction pathway. Oncogene 25: 7009-7018, 2006.

30. Woo MS, Jung SH, Kim SY, Hyun JW, Ko KH, Kim WK and Kim HS: Curcumin suppresses phorbol ester-induced matrix metalloproteinase-9 expression by inhibiting the PKC to MAPK signaling pathways in human astroglioma cells. Biochem Biophys Res Commun 335: 1017-1025, 2005. 